\title{
Internet skills as an influencer for adoption of digital innovations in a technologically emerging nation: India
}

\author{
Dorothy Dutta and M.K. Sarma \\ Department of Business Administration, Tezpur University, Naapam, India
}

\begin{abstract}
Purpose - The advent of technology has enabled frequent innovations in the digital modes of doing business. While some users are reluctant to adopt one, others have made it their way of life. The purpose of this study is to find out the approximate time frame of a digital user in an emerging economy like India to adopt their favorite digital application. The importance of an individual's level of internet skills is explored in the aspect of adopting digital innovations.

Design/methodology/approach - The study follows a quantitative approach where data collected from both primary and secondary sources are analyzed to arrive at the results. In total, 837 responses collected with the help of a structured questionnaire are entered and analyzed using SPSS. Multinomial logistic regression is the statistical tool used in the research.

Findings - Five sets of adopter categories based on Rogers (1983) are created using an adoption score and are represented in a Time Horizon to understand better. The Unaffected adopter category is used as the reference point to compare the set of internet skills against each of the other five categories. The five sets of categories comprising the internet skills depict interesting results in the case of all the four comparisons made. Social skills are not seen to have any influence on a user being an Innovator or Early Adopter as compared to an Unaffected user. It is also established that Operational and Creative skills play important role in users' probability of being an innovator, early adopter and early majority compared to being unaffected.

Originality/value - The study analyzes the role of internet skills in the process of adopting digital innovations. The role of internet skill although is associated with every aspect of the digital revolution taking place all over, its application including the direct score of a digital user's level of internet skills is not found in the literature.
\end{abstract}

Keywords Internet, Innovation, Skills, Digital, Adopter

Paper type Research paper

\section{Introduction}

Digital innovations are happening all over the globe changing the traditional methods of providing and availing a variety of services. Thompson (1965) defined innovation to be a process of generating, accepting and implementing new ideas in products or services. The increasing pace of advanced technologies modes of operating businesses has shifted from

(C) Dorothy Dutta and M.K. Sarma. Published in Vilakshan - XIMB Journal of Management. Published by Emerald Publishing Limited. This article is published under the Creative Commons Attribution (CC BY 4.0) licence. Anyone may reproduce, distribute, translate and create derivative works of this article (for both commercial and non-commercial purposes), subject to full attribution to the original publication and authors. The full terms of this licence maybe seen at http:// creativecommons.org/licences/by/4.0/legalcode

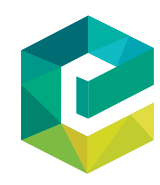

Vilakshan - XIMB Journal of Management Vol. 20 No. 1,2023 pp. $25-41$ 
traditional brick and mortar to online platforms. The competition among these digital platforms is quite high, and hence, to keep up with its marketers need to make use of the technologies to innovate their digital platforms. Agostini et al. (2020) stated that it is the remarkable growth of digital technologies that has contributed to the innovations occurring online. The introduction of newer technologies has opened up a wide range of possibilities for marketers to innovate online. Innovations help marketers generate profits and keep their position in the market intact. The innovations, however, in the digital space can be broadly classified into two types-radical and incremental. Where the introduction of radical innovations like online shopping and internet banking have made prominent changes in the way of our daily lives; incremental innovations in the form of smaller improvements have helped firms gain profits in the market (Pisano, 2014). Digital innovations in either form have become an inseparable part of the digital users. The optimum utilization of these innovations depends on a crucial aspect of the users' which is their level of internet skills (Wittendorp, 2017). The level of internet skills possessed by each individual differs based on their experience with the internet. While some might find adapting to these frequent digital innovations exciting, others might be reluctant in doing so as they are rapid and difficult to control (Henfridsson et al., 2014). The digital users especially in a country like India where the digital divide scenario exists, there arises the chances of users with a lower level of internet skills losing their interest further in coming up with the digital age. Internet skills here play an important role as the majority of chances of the users adopting frequent digital innovations are based on it. Past literature has aptly captured the factors contributing to the adoption of radical innovations such as internet banking and online shopping. However, an insight into the role of internet skills in this entire process would be quite intriguing. The adoption of innovations has been in the past highly associated with the diffusion of innovation theory put forward by Rogers (1983). The adopter categories mentioned in the theory summarizes the kind of individuals adopting a particular innovation. This research attempts to explore the role of internet skills in adopting the digital innovations put out by marketers in a frequent manner concerning the digital users in a country where instances of the digital divide are reported at a significant rate. The adopter categories would be used to formulate the kind of individuals existing in a developing nation like India. The research would provide a clear idea about internet skills which can further help in the formulation of strategies for targeting users in a developing country with a continuously increasing new internet user base.

\section{Digital innovations}

Digital innovations are the new trend grasping the attention of marketers. Marketers invest in various novel information technology processes in their organizational structures that help them to generate benefits and help them strategically deal with the entire digital transformation system happening all over (Wiesböck and Hess, 2020). Studies about the adoption of digital innovations among users have been conducted in the past on a large scale. Ebermann et al. (2016) talked about the adoption of digital innovations among the natives and immigrants for digitization. The study revealed the impact of digital nativeness on forming the attitude toward the intention to use digital innovations. Another factor that is found to have a significant influence is the socio-psychological principles. Although the adoption of digital innovations is occurring in the present day the amount of time taken to adopt is quite high. Jhanmir and Cavadas (2018) found that the factors responsible for the late adoption of digital innovations are users' attitude toward technology, innovativeness of the consumer, the global image of the brand and the profile of lead-user. One essential tip for encouraging the adoption of digital innovation is to increase the 
positive attitude of consumers toward technology. Talwar et al. (2020) presented a systematic review of the resistance seen in consumers toward digital innovations. Barriers in the form of socio-demographic factors, the risk involved, the value generated, traditional methods of doing things, the image associated, etc. leads to the postponement, rejection or opposition to the digital innovations. These barriers are often resisted by the characteristics of the innovation and that of the consumer. Apart from these factors level of internet skills among the users can also be visualized as a barrier to adopting digital innovations. Wittendorp (2017) defined the difference in the levels of internet skills of the users as the digital divide. Although there exist other reasons for the digital divide in emerging countries such as socio-demographic conditions, political and economic situation (Chakrabarty and Dutta, 2014); the difference in the level of internet skills is also a threat. To provide maximum benefits to the users of the internet is to ensure that they are skilled enough to avail these facilities provided to them via digitalization. A detailed analysis of the different characteristics of internet skills is discussed in the next sections.

\section{Diffusion of innovations}

The literature about the diffusion of innovations is largely contributed by Rogers (1983). The theories forwarded by the author have immense value in the current literature aspect as well. For the study, Rogers adopter categories for innovations have been considered and are modified according to the requirement of the study. The rate of adoption is an important measure when talking about adopter categories as the rate of adoption is nothing but the speed with which a relative number of individuals in a social system adopt an innovation. The course of adopting these innovations might vary from immediately after the launch or it might extend until the product is saturated in the market. Rogers (1983) based on the rate of adoption of innovations categorized individuals in a social system into five categories, namely- innovators, early adopters, early majority, late majority and laggards. The characteristics guiding each of these categories are different and have been explained below.

- Innovators - users in this category can cope with higher levels of uncertainty in an innovation. They source their information through their wide networks and mostly are the first ones to adopt an innovation.

- Early adopters - they fall next to innovators and play an important role in motivating other members of the social system to use the innovations. They act as influencers and are looking up for information in the social group.

- Early majority - the individuals under this category adopt the innovation before an average number of people in the society do. They do take their amount of time to analyze the innovation before becoming an active user. As mentioned by Rogers (1983) the early adopters do have deliberate willingness to adopt the innovations but they are mostly not the ones to lead.

- Late majority - this stage of the individual is similar to the previous category as they wait for their peers in the social system to adopt the innovation and then go on to trying them. They have lower thresholds for uncertainties involved with the innovations.

- Laggards - these refer to the last category of adopters who carry a traditionalistic viewpoint and are not quite own to adopting novel ideas. The amount of time taken for the laggards to arrive at an adoption decision is quite late. 
Goh and Sigala (2020) studied the diffusion of innovation to teaching in the hospitality sector. The integration of information and communication technologies (ICTs) into the education sector facilitates many modern aspects of learning and provides an optimum situation for conducting modules. Diffusion of innovation theory has been used here as a theoretical base to understand the changes in the educational sector concerning technological innovations. The recognition of the different adopter types by the administration is important as not every individual can adopt at the same time. The faculties teaching with technological aids must be encouraged toward forming a positive attitude for these novel methods of teaching. The technical support to effectively use the measures must be provided to the faculty members by all the administrative workers. As $68 \%$ of the adopter categories comprise an early and late majority of faculties creating critical mass is very important.

Vargo et al. (2020) redefined the diffusion of innovation framework and created a new idea including processes that are service-centered, involve the ecosystem and have an institutional lens. The study involves the aspect of technological innovations that have altered the recent happenings across the globe. The framework does not consider one actor as an innovator and the other as a consumer, but it integrates all the actors and considers diffusion as an important part of the process. The adoption of technological innovations by more and more people helps in the growth and development of knowledge to establish a socio-technical environment in the future.

\section{Internet skills}

It was stated by van Deursen and van Dijk (2010a, 2010b) that although several countries had a high rate of diffusion of the internet the optimum utilization of the same remains questionable. The role of internet skills in today's situation does not only comply with basic button knowledge but also is extended to providing social support through communication too (van Deursen et al., 2016). One most important barrier that arises in emerging countries like India is the digital divide.

Livingstone et al. (2017) studied the role of the internet in parental mediation to maximize the online opportunities for their kids while minimizing the online risks. The survey was conducted among a total of 6,400 respondents who were parents to 6-14-year-old kids. It was seen that parents who were confident about their digital skills tried to incorporate the same into their children while building safety considerations around it. On the other hand, the parents with lesser digital skills emerge as more restrictive in terms of their kids' online behavior while having a scope for these parents to refine their digital skills in the future to cope up with their child's opportunities and risks online.

Helsper and van Deursen (2017) conducted a study among 1,149 respondents in The Netherlands to know about the factors that predict the use of social support networks to help an individual using the internet in areas suffering from the digital divide. The reason for using the support is the lack of internet skills. It could either be for one of the reasons - one being belief in one's internet skills and the other is one's actual level of internet skills. It was found that there were no significant socio-cultural, socio-economic and social differences in the availability of potential, as well as actual support. It was also seen that mostly informal support from family or friends was asked by the ones who were retired or have lower levels of digital resources, but one with more socioeconomic resources went to formal sources for help like experts or co-workers. The authors said that the problem of the digital divide remained even with the existence of 
support sources because the ones who experience the most problem were the ones who were unable to reach out to high-quality support.

van Deursen and Helsper (2018) studied the Dutch population to find if any kind of economic, social, cultural and personal engagement made with the internet results in various outcomes of economic, social, cultural and personal nature. An online survey was conducted among beginner and advanced level internet users with a total of 1,101 responses. The results show that the personal and social use of the internet has the most collateral benefits. The economic use of the internet, on the other hand, was found

to be related to economic outcomes mostly. While considering narrow approaches to digital exclusion skills like navigation and softer communication skills are effective for translating uses into outcomes. However, those who have high creative skills have higher quantity but lower quality of outcomes; in the case of social skills, there was negative or no effect on the quantity of cultural and social outcomes but had a positive quality of outcomes. Operational skills were seen to have no direct relation to achieving outcomes.

Internet skills as found by the above researchers are not only constrained to browsing through the device but also help in providing various personal, social and economic outcomes. Effective use of the internet enhances one's internet skills and results in narrowing the digital divide as much as possible. In the present day, it could be well predicted that the digital methods of doing business would sustain in the future, countries like India need to know and understand the status of their citizens when it comes to using the internet optimally. In an era of technological advancement, there ought to be disruptions coming into the digital space and according to Maiti et al. (2020), the role of technology and other ICT-based opportunities could result in certain contrasting effects when talking about developing economies like India. The first one is that there might be a positive impact because of technological advancements in ICT whether it is economic or social growth. On the other hand, there arises the question of how well these developing nations are catching up with the fast pace of technology having disparities in their infrastructures, education and income levels.

It is seen that diffusion of innovations for technological advancement has gained the attention of scholars in recent time, this study is, thus an attempt direction of analyzing the current situation of users' internet skills in an emerging economy like India and its impact on the adoption of digital innovations. Singh (2018) mentioned that as per reports of Bain and Company there would be 600 million Indians with smartphones in the next seven years (i.e. within 2025) with each transacting digitally and consuming content. According to the Internet and Mobile Association of India (2019), the number of active mobile internet users is already at 451 million in India. There is an increasing rate of mobile internet users in the country which is expected to grow shortly. This implies that there are changes in the increase of availing digital platforms as well. However, the big leap in the use of digital platforms happened in India since 2016 when demonetization took place (Sharma, 2018). According to Bhat et al. (2018), after the demonetization period, online dealings saw a rise due to the provision of e-wallets and different modes of online payments. Incidentally, India ranked second, namely, growth in the digital adoption index during the period of 2014-2017 only after Indonesia (Kaka et al., 2019). Digital transformations worldwide are influencing the developments of societies (Zimmermann, 2016). For India, as an emerging nation, it is important to grasp every opportunity of development from digital transformation. For example, we can look at one sector that reported a significant growth in adopting digital modes is the travel and hospitality sector. As per The Economic Times Travel (2018), India would now grow at a rate of $14.8 \%$ annually during $2017-2021$ in terms of online booking. 
However, in this competitive era of digitalization, there are chances that digital platform providers might lose their users to competitors if they are unable to sustain the innovations they have introduced. In such a situation it is the incremental innovations that provide help to the digital platform providers to retain their consumers' interests in this dynamic digital environment.

Therefore, the research objective for the study is, thus -

To determine the impact of users' internet skills in adopting innovations in the digital platforms.

\section{Research methodology}

The study takes a quantitative approach wherein a structured questionnaire is used to collect the information necessary for this research. Measurement of the level of internet skills of a digital user is done with the help of the internet skills scale (ISS) developed by van Deursen et al. (2016). The scale is specially designed by incorporating the missing aspects in the past literature of a standard measure for internet skills. ISS is categorized into five types of skills that cumulate each criterion for an appropriate understanding of the internet. The five-set of skills are as follows-

(1) Operational - operational skills are defined as a set of basic skills which is required by an individual $d$ to use internet technology (van Deursen and van Dijk, 2010a, 2010b).

(2) Information navigation - these are the set of skills whose presence help the user to find information online without facing any such serious issues with navigation (O’Doherty et al., 2019).

(3) Social - social skills are known as the communicating medium required to encode or decode the messages received online to construct, understand and exchange its meaning with other human beings while using a similar system (van Deursen and van Dijk, 2014).

(4) Creative - creative skills are required to create online content of acceptable quality with the help of various mediums such as textual, audio, video, multimedia or any sort of remixed content (van Deursen and van Dijk, 2014).

(5) Mobile - mobile skills are the basic set of skills required to use mobile devices for browsing through the internet (van Deursen et al., 2016).

ISS consists of 23 items in a five-point Likert type scale ranging from "Not at all true of me" through "Not very true of me," "Neither," "Mostly true of me" to "Very true of me."

To segregate the adopter categories three questions were asked in the questionnaire. One question being closed-ended where the digital user needs to answer on a dichotomous scale (Yes/No) if he/she remembers any digital innovation that has made their lives easier. The ones responding "No" automatically fall into the "Unaffected" category of user. While the ones ticking the affirmative option answers the next two open-ended questions. In the first one, he/she needs to fill in the name of the innovation they recalled while answering the previous question and second they need to enter the approximate time (month/year) when they started using the innovation. From the innovation and time mentioned by the user, the launch dates for each of the mentioned services are attained through secondary sources to calculate an adoption score. The adoption score would help in segmenting the digital users into their type of adopter category. The adopter categories assumed here are those by Rogers (1983) due to the similarities in the situation of research. However, the modifications made in the study on these adopter categories are as follows: 
Laggards

Rogers (1983) categorized his adopter categories into five stages. However, here in the case of this research, the last two categories in the list have been classified as one, namely - late majority and laggards. As the maximum number of users are seen to fall into the category of unaffected, these two categories have been merged as they both represent a traditional section of users who are skeptical about letting go of conventional means of doing things they followed. They can be specified as the last ones to adopt an innovation who are only willing to do so once the innovation has been established as a success in the market.

\section{Unaffected}

As mentioned earlier this is an addition to the Rogers (1983) adopter categories as per the need of the study. The ones in this category are not at all impacted by the launch of any kind of digital innovation occurring online. They have no experience of an innovation that made a striking difference in their day-to-day lives after being introduced. The term quite explains their state in this digital innovation situation - not affected by digital transitions at all.

The adoption score is calculated using the following formula -

$$
\text { Adoption Score }=D U \div D L
$$

where

$$
\begin{aligned}
& D_{U}=\text { Duration of using the mentioned online service in years; and } \\
& D_{L}=\text { Duration of the launch of the mentioned online service in years. }
\end{aligned}
$$

A detailed discussion on how the adopter categories is formulated using the adoption score formula is offered in the next section.

A total of 837 responses have been collected for the study using judgment sampling. It is required that the respondents chosen for the study have experience of using digital platforms, hence, the criteria for judgment sampling have been laid down for selecting the respondents. As only various digital platform users are sought after for the study it is important to lay down the criteria for selecting the respondents. The respondents are chosen from four districts in the state of Assam. The state captures the aspect of an emerging economy with an $86 \%$ rural population and an increasing internet user base. Employment livelihood and quality index (ELQI) is used to select the districts with the best livelihood and quality of life; as internet usage is found to be dependent on factors such as per capita income (Pew Research Center, 2014) which is also a factor in the ELQI along with other socioeconomic elements. The top four districts under ELQI are - Kamrup Metropolitan, Jorhat, Nalbari and Sibsagar.

For the analysis, the dependent variable considered here are the adopter categories and the independent variables are the five skills that comprise the internet skills. The association between the two would reflect the influence of each set of skills in determining the adopter category that a respondent would fall into. The research hypotheses are, thus formulated using the adopter categories as the dependent variable and each of the five skills as the independent variables.

The data collected are analyzed using MS Excel and IBM SPSS.

\section{Analysis}

The demographic representation of the samples are as follows

As per Keelery (2020), a maximum number of internet users in India are in the age bracket of 20-29 years of age with the number being minimum for the age group of above 40 years. 
XJM

20,1

32

\section{Table 1.}

Demographic representation
The sample thus is a representation of the same and the number of respondents in the age group of 15-34 years is the maximum.

To arrive at the adopter categories and eventually to the time horizon, the process is followed as mentioned by Dutta and Sarma (2021). The procedure has been explained in detail in the upcoming section as well. The responses for the digital innovation that made the lives of the users easier recorded a variety of responses. Although some of the responses were quite specific including the exact name of the service provider, some responses were vague. However, after scrutinizing each of these responses are divided into eight categories. Table 1 below shows these categories along with the frequency of their mentions and their launch dates in the region of the study with its source of information (Table 2).

\begin{tabular}{lcr}
\hline Demographics & Frequency & $(\%)$ \\
\hline Residence & & \\
Urban & 418 & 49.9 \\
Non-urban & 419 & 50.1 \\
Age & & 57.6 \\
15-24 & 482 & 34.9 \\
25-34 & 292 & 4.3 \\
35-44 & 36 & 3.1 \\
More than 45-54 & 27 & 49.0 \\
Gender & & 51.0 \\
Male & 410 & 34.9 \\
Female & 427 & 36.2 \\
Education level & & 28.9 \\
Undergraduate & 292 & 54.0 \\
Graduate & 303 & 46.0 \\
Postgraduate & 242 & \\
Income & & \\
Non-earning & 452 & \\
Earning & 385 &
\end{tabular}

\begin{tabular}{lll}
\hline Type of service & $\begin{array}{l}\text { Frequency } \\
(\text { percentage })\end{array}$ & Launch date \\
\hline Banking & $\begin{array}{l}\text { 100 } \\
(11.9)\end{array}$ & 1996 (Iyengar and Belvalkar, 2010) \\
Shopping & $\begin{array}{l}120 \\
(14.3)\end{array}$ & 2007 (Flipkart Stories, 2017) \\
Information seeking & 32 & 1998 (as in most of the cases the term "Google" was mentioned \\
& $(3.9)$ & the date for the same is taken) \\
Bookings & 80 & 2002 (Khandelwal,2019) \\
& $(9.6)$ & 2013 (Kochar, 2016) \\
Bill payments & 15 & 2004 (Mehra, 2021) \\
Social media & $(1.8)$ & 2018 (Financial Express, 2018) \\
Food delivery & 22 & 2006 (CIOL Bureau, 2006) \\
Wallets & $(2.6)$ & \\
& $(2.5)$ &
\end{tabular}

Table 2.

List of digital innovations with frequencies and launch date 
There is a total of $410(49 \%)$ respondents who recalled the name of one such digital innovation that has changed their way of life. However, another $427(51 \%)$ interviewees responded in the other category, and hence, are categorized as "Unaffected" users. The launch dates are set as per the secondary information achieved (refer to Table 1) based on the brand name or type of online service data provided by the users. After the launch dates are found for each of these services individual adoption scores are calculated. The four adopter categories are then divided using the visual binning process in SPSS. The cut-off points for creating these distinct groups of categories are \pm 1 standard deviation. The cut-off range set up from the process is as follows -

From the categorization, it is seen that most of the respondents fall into the category of early majority $(31.1 \%)$. It explains the current situation of the country where the numbers of internet users are constantly increasing and that a large part of them prefer using the online innovative services once they have been tried and tested. Next, in the line are the early adopters $(10.5 \%)$. Based on the increasing number of people online creating a niche and providing their share of followers' experiences with innovation the number of users in this category can be expected to grow in the future. Then, there is the category of Innovators $(6.1 \%)$ followed by Laggards $(1.3 \%)$. These are the guys who adapt innovations that have died out. From one angle it is not bad that we have a negligible amount of laggards. In a way, it shows that those who are interested in innovation adoption have readily embraced the same. However, the main motivation for the digital service providers must be to convert the majority of early adopters and early majority into innovators. When there is an increasing number of innovators in the block the service providers can effectively introduce incremental innovations to further enhance their offering. To better understand the status of each of these adopter categories, a graphical representation in the form of a time horizon is being formulated below - (Figure 1).

As mentioned above ISS is used to find out the level of internet skills in each of the respondents. The five sets of skills would be analyzed opposite the five adopter categories using multinomial logistic regression. This type of regression is ideal for analyzing the impact of independent variables on a nominal dependent variable with more than two categories to measure the probability of group membership. The method allows us to predict

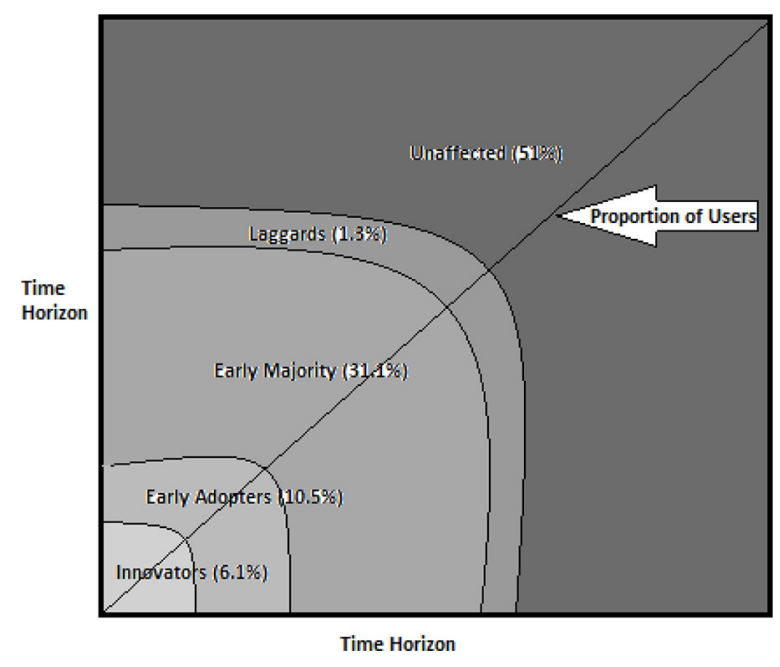

Figure 1. Time horizon for adoption of digital innovations

Internet skills as an influencer 
$\mathrm{XJM}$

20,1

Table 3.

Adopter categories with range the probabilities of the various outcomes in a categorical dependent variable concerning several independent variables.

The dependent variable here would be the five adopter categories and the independent variables are the five individual sets of skills that combine to formulate the level of internet skills. As the Unaffected category of users depicts the ones not actively using any kind of digital innovation, they would be set as the reference category to present a comparison with each group of user categories.

As mentioned by Grilo et al. (2017), let us consider Y to be the dependent variable (adopter categories in our case) with $\mathrm{K}=5$ categories (Innovators, Early Adopters, Early Majority, Laggards and Unaffected) would generate five logistic models. Once the reference category is standardized (Unaffected is the reference category here), the probability of $\mathrm{Y}$ taking values from each of these five categories could be computed. Thus, in matrix notation, if $X$ is the matrix representing the independent variables and beta $(\beta)$ is the vector of the coefficients is represented as follows:

$$
\mathrm{P}(\mathrm{Y}=1 \mid \mathrm{X})=\frac{1}{1+\sum_{k=2}^{5} e^{X \beta_{k}}}, \mathrm{P}(\mathrm{Y}=2 \mid \mathrm{X})=\frac{e^{X \beta_{2}}}{1+\sum_{k=2}^{5} e^{X \beta_{k}}} \ldots \mathrm{P}(\mathrm{Y}=5 \mid \mathrm{X})=\frac{e^{X \beta_{5}}}{1+\sum_{k=2}^{5} e^{X \beta_{k}}}
$$

Now for K-1=, 4 odds for every category of $\mathrm{Y}$ for the reference category are given by:

$$
\frac{\mathrm{P}(\mathrm{Y}=2 \mid \mathrm{X})}{\mathrm{P}(\mathrm{Y}=1 \mid \mathrm{X})}=e^{X \beta_{2}} ; \frac{\mathrm{P}(\mathrm{Y}=3 \mid \mathrm{X})}{\mathrm{P}(\mathrm{Y}=1 \mid \mathrm{X})}=e^{X \beta_{3}} ; \frac{\mathrm{P}(\mathrm{Y}=4 \mid \mathrm{X})}{\mathrm{P}(\mathrm{Y}=1 \mid \mathrm{X})}=e^{X \beta_{4}} ; \frac{\mathrm{P}(\mathrm{Y}=5 \mid \mathrm{X})}{\mathrm{P}(\mathrm{Y}=1 \mid \mathrm{X})}=e^{X \beta_{5}}
$$

Thus, the log odds are obtained by adding logarithm to them and getting the multi-equation model for the reference category. The comparison between the reference category and each of the other four categories is varied due to the difference in the values of each of these explanatory variables:

$$
\begin{aligned}
\ln \frac{\mathrm{P}(\mathrm{Y}=2 \mid \mathrm{X})}{\mathrm{P}(\mathrm{Y}=1 \mid \mathrm{X})} & =\mathrm{X} \beta_{2} ; \ln \frac{\mathrm{P}(\mathrm{Y}=3 \mid \mathrm{X})}{\mathrm{P}(\mathrm{Y}=1 \mid \mathrm{X})} \quad=; \quad \ln \frac{\mathrm{P}(\mathrm{Y}=4 \mid \mathrm{X})}{\mathrm{P}(\mathrm{Y}=1 \mid \mathrm{X})} \\
& =\mathrm{X} \beta_{4} ; \ln \frac{\mathrm{P}(\mathrm{Y}=5 \mid \mathrm{X})}{\mathrm{P}(\mathrm{Y}=1 \mid \mathrm{X})}=\mathrm{X} \beta_{5}
\end{aligned}
$$

To determine if the data perfectly fit with the multinomial logistic regression there are a few parameters that need to be tested to determine the model fit of the same. The next tables hold the information about the analysis conducted.

Tables $3-5$ include the model fit criteria for the variables in question. The likelihood ratio tests show a $p$-value of 0.000 which is less than the 0.05 level of significance, indicating a

\begin{tabular}{ll}
\hline Adopter category & Range \\
\hline Innovators & 0.52 plus \\
Early adopters & 0.28 and 0.51 \\
Early majority & within 0.05 and 00.27 \\
Laggards & more than equal to 0.04 \\
\hline
\end{tabular}


better significant model fit than the null model. Coming to the Pearson and Deviance values of significance for goodness-of-fit, it is an indication of a good fit for both the tests the level of significance is above the 0.05 level. Thus, overall, the model is determined to fit (Dey and Raheem, 2016) for conducting the next part of the analysis with an $R^{2}$ value change of $12.9 \%$.

Internet skills as an influencer

Next, we move on to look at the likelihood ratio tests for each of the independent variables in Table 6 below (Table 7 ).

From the five sets of skills, it is seen that operational, information navigation, creative and mobile skills have significant results at 0.05 levels. The only set of skills that is not seen to exert any significant overall effect on the adoption score is social skills. Now, we move on to look at the parameter estimates of each of these skills with the adopter categories in detail (Table 8).

With the unaffected user category set as a reference, it is seen that in the case of laggards only information navigation skills significantly predict if one falls into either of the group. For the Early Majority, it is interesting to note that all five sets of skills are significant. Coming to early adopters operational, information navigation and creative skills are statistically significant. While analyzing the last category innovators all the four sets of skills except that for social skills are significantly associated. Now, let us interpret the odds ratio to get a clear understanding of these set skills in each category.

In the case of the laggards and unaffected category, the only variable significant is Information Navigation wherein the $\beta$-value is negative $(-1.025)$. The odds ratio for the same stands at 0.359 which is less than 1 . This indicates that for a one unit increase in the

\begin{tabular}{|c|c|c|c|c|c|c|}
\hline Model & \multicolumn{3}{|c|}{ Model fitting criteria } & \multicolumn{3}{|c|}{ Likelihood ratio tests } \\
\hline & AIC & $\mathrm{BIC}$ & -2 Log likelihood & Chi-Square $\left(\chi^{2}\right)$ & df & Sig. \\
\hline Intercept only & $1,746.776$ & $1,765.618$ & $1,738.776$ & & & \\
\hline Final & $1,673.693$ & $1,786.745$ & $1,625.693$ & 113.083 & 20 & 0.000 \\
\hline
\end{tabular}

Note: $\mathrm{AIC}=$ Akaike Information Criterion; $\mathrm{BIC}=$ Bayesian Information Criterion

Table 4. Model fitting information

\begin{tabular}{lccrr}
\hline Residuals & $\chi^{2}$ & df & Sig. & Table 5. \\
Pearson & $2,559.993$ & 2,544 & 0.408 & Goodness-of-fit \\
Deviance & $1,521.918$ & 2,544 & 1.000 & G \\
\hline
\end{tabular}

\begin{tabular}{llr} 
Cox and snell & 0.129 & Table 6. \\
\hline Nagelkerke & 0.143 & Pseudo $R^{2}$ \\
\hline
\end{tabular}

\begin{tabular}{|c|c|c|c|c|c|}
\hline Effect & -2 Log likelihood of the reduced model & $\chi^{2}$ & $\mathrm{df}$ & Sig. & \\
\hline Intercept & $1,631.088$ & 5.395 & 4 & 0.249 & \\
\hline Operational & $1,688.176$ & 62.483 & 4 & 0.000 & \\
\hline Information navigation & $1,665.163$ & 39.471 & 4 & 0.000 & \\
\hline Social & $1,635.005$ & 9.312 & 4 & 0.054 & \\
\hline Creative & $1,642.888$ & 17.196 & 4 & 0.002 & Table 7 \\
\hline Mobile & $1,643.524$ & 17.831 & 4 & 0.001 & Likelihood ratio tests \\
\hline
\end{tabular}




\begin{tabular}{|c|c|c|c|c|c|c|}
\hline \multirow{5}{*}{$\begin{array}{l}\text { XJM } \\
20,1\end{array}$} & Categories & Internet skills & $\mathrm{B}$ & $\mathrm{df}$ & Sig. & $\operatorname{Exp}(\mathrm{B})$ \\
\hline & Laggards & Intercept & -2.694 & 1 & 0.204 & \\
\hline & & Operational & 0.936 & 1 & 0.127 & 2.549 \\
\hline & & Information navigation & -1.025 & 1 & 0.027 & 0.359 \\
\hline & & Social & 0.52 & 1 & 0.417 & 1.682 \\
\hline \multirow{15}{*}{36} & & Creative & -0.052 & 1 & 0.885 & 0.949 \\
\hline & & Mobile & -0.75 & 1 & 0.11 & 0.472 \\
\hline & Early majority & Intercept & 0.131 & 1 & 0.823 & \\
\hline & & Operational & 1.179 & 1 & 0 & 3.25 \\
\hline & & Information navigation & -0.769 & 1 & 0 & 0.463 \\
\hline & & Social & -0.424 & 1 & 0.01 & 0.655 \\
\hline & & Creative & 0.203 & 1 & 0.029 & 1.225 \\
\hline & & Mobile & -0.362 & 1 & 0.015 & 0.696 \\
\hline & Early adopters & Intercept & -0.277 & 1 & 0.769 & \\
\hline & & Operational & 0.708 & 1 & 0.002 & 2.03 \\
\hline & & Information navigation & -0.806 & 1 & 0 & 0.446 \\
\hline & & Social & -0.259 & 1 & 0.274 & 0.772 \\
\hline & & Creative & 0.369 & 1 & 0.008 & 1.447 \\
\hline & & Mobile & -0.314 & 1 & 0.138 & 0.73 \\
\hline & Innovators & Intercept & -1.741 & 1 & 0.095 & \\
\hline & & Operational & 0.708 & 1 & 0.019 & 2.029 \\
\hline Table 8. & & Information navigation & -0.525 & 1 & 0.05 & 0.592 \\
\hline Parameter estimates & & Social & 0.155 & 1 & 0.645 & 1.167 \\
\hline for each of the & & Creative & 0.6 & 1 & 0.001 & 1.823 \\
\hline adopter categories & & Mobile & -0.946 & 1 & 0 & 0.388 \\
\hline
\end{tabular}

level of information navigation skills the risk of an individual falling into a category of laggards decreases 0.359 times than that in the unaffected category. Now, in the case of the early majority, it is seen that two of the variables, namely - operational skills and creative skills have an adjusted odds ratio of more than 1 which is significant. This implies with every unit increase in operational and creative skills in a digital user the risk of them being in the early majority increases versus the unaffected category. However, on the contrary for one unit increase in the information navigation, social and mobile skills the risk of them being in the early majority adopter category goes down by $0.463,0.655$ and 0.696 , respectively, then that would have been unaffected. For both early adopters and innovators, similar characteristics are predicted in the case of all five variables. While social skills are not significant in both the cases, operational and creative skills show the increasing risk of being in the early adopter and innovators category increases than in unaffected for every unit rise. On the other hand, for information navigation and mobile skills the risk for their respective categories decreases than that for being unaffected.

\section{Discussion}

Based on the responses recorded it is seen that when it comes to adopting a digital innovation that has made one's life easier, most of the respondents could not specifically recall any such instance that has made a mark in their lives. These fall into the unaffected category who either have not had any life-changing experience with a service going online or they prefer the traditional methods of availing day-to-day services. Out of the percentage of users who did have a favorite online service that they go back again and again to experience, the majority of them are seen to fall under the early majority. These types of users prefer to take their amount of time before adopting an innovation. It is mostly after 
receiving positive feedback from their peers that they indulge in availing of those services and finally adopt them. They take more time to adopt the innovations but do it before the laggards who adopt an innovation only after it is outdated in the market.

Internet skills as an influencer

\section{Theoretical contributions}

The study found that the least percent of users fall into the category of laggards which is a significant revelation. Although in India with the majority of the rural population and limited internet reach the number of users out of the ones adopting digital innovations, the laggards being the least is a relatively good sign. The early adopters are the second in number followed by innovators. The leap from being an early majority to an early adopter could prove to be quite beneficial in improving the digital hold in the country. Early adopters take lesser time to adapt and are often seen as the influencers in society. An increasing number of early adopters would ensure that more people are influenced in adopting the innovations and imply a better product/service reach.

The internet skills when associated with these five adopter categories some very interesting points are established. First, when the laggards are put against comparison with the unaffected it is seen that the only skill that had an influence is information navigation. The increase in per unit of this skill suggests that a user has the risk of tilting toward being an unaffected user than a laggard. It means that if the user increases his level of information navigation he is more likely to browse through a varied lot of digital options rather than adopting an old backdated innovation. For the early majority if they have an increase in their operational and creative skills they have the probability of falling into this category rather than unaffected. Operational skills refer to the ease with which one can handle the operating aspects of the internet and creative skills ensure that the user is quite innovative and likes to showcase them online. Hence, a user who excels in these skills even by one unit would prefer catching up with the existing digital innovations that serve their purpose other than not picking up an effective tool for their use. A similar situation holds for operational and creative skills is found to hold for early adopters and innovators. However, for innovators and early adopters, the role of social skills is seen to be insignificant. This indicates that users who are active in trying out an innovation online clearly are not looking for it to communicate with others but are more driven due to its benefits. In both cases, it is seen that when there is an increase in one's information navigation and mobile skills they tend to fall under the unaffected category. This could result because of one's caliber to browse information smoothly and having greater knowledge about the mobile device they are operating on they like to look for all kinds of innovations available online rather than using one of them.

\section{Practical contributions of the research}

The results found from the analysis conducted aptly portray the role of internet skills in the adoption of innovations in digital platforms. The study highlights the exact sub-skills in determining one's level of internet skills that need to be focused upon depending on the type of adopter category one falls into. The significant impact of the role of internet skills in adopting digital innovations is established. As found by van Deursen and van Dijk (2018) providing physical access to consumers along with internet skills can result in the reduction of the digital divide in any country whether it is a developed nation or is in the developing stage, this research shows the importance of acknowledging the different levels of internet skills possessed by users in a developing economy and applying measures to cure the digital divide situation. The digital divide situation in India is due to the lack of resources in the rural areas compared to that of the urban areas. India with a maximum of rural residents 
and a growing internet user base, the study displays the policies and strategies that could be implemented to make these users accustomed to the process of innovation in the digital era.

\section{Conclusion}

The advent of digital platforms has enabled many service providers to cater their offerings to everyone under the digital reach; whether it is an internet user from a rural village or someone residing in an urban locality. Online methods of offering services have gained momentum in recent years and can be expected to go on for a long time. As in this study, we tried to find out the scenario prevailing when it comes to digital users adopting an innovation online in a country like India where the digital divide is a consistent concern. The role of individuals' internet skills has also been included to find out if it has any influence on the time frame taken by an individual to adopt a digital innovation. The number of users in each group of adopter categories can be used to represent the scenario prevailing in the country for the adoption of digital innovations. With the number of users in the unaffected category being the highest the marketers at this stage must strategize in converting the maximum of them to innovators or early adopters. This would ensure that within a short span of introducing innovation in their digital platform users would adopt them. Rogers (1983) adopter categories are modified during the research where a new category, namely, "Unaffected" is seen to be included keeping in mind the situation in a developing nation. The role of internet skills concerning these adopter categories is well stated in this study and marketers can incorporate them into their marketing modules. The study reveals certain characteristics based on the set of internet skills, which are influencing each of the adopter categories. The time horizon itself helps us to find out the percentage of users who are most likely to be found in a country with the cause of the digital divide. The set of skills that corresponds mostly to the ideal adopter category has been highlighted in the study. This could be focused on and used to convert a maximum number of digital users into the innovators and early adopter categories so that they use innovation as soon as it is launched and help reduce the time horizon. However, the most alarming adopter categories are the unaffected who are the ones using digital innovations but are not enticed enough to go back and use them repeatedly. Reduction in the number of users in the unaffected category can generate better customer outcomes (and thus business outcomes) for the service providers and help to improve the overall digitalization situation in the country.

\section{Limitation and scope for further research}

The study has been conducted within a stipulated period, and thus the time horizon created includes digital innovations corresponding to a specific period. The study is further conducted from the perspective of the consumer and the marketer's point of view is not incorporated. In future research, however, research from the marketers' perspective can be conducted. For the adopter categories, a lower section of users is seen to fall into the innovators and laggard's category compared to the other categories. This means that users prefer adopting an innovation only when a certain period has passed from the time of launch. The reason behind this kind of cognition in the mind of the users could also be an interesting area to deal with.

\section{References}

Agostini, L., Galati, F. and Gastaldi, L. (2020), "The digitalization of the innovation process challenges and opportunities from a management perspective", European Journal of Innovation Management, Vol. 23 No. 1, pp. 1-12, doi: 10.1108/EJIM-11-2019-0330. 
Bhat, D.A., Batool, M. and Bhat, I.M. (2018), "Examining the post waves of demonitisation on indian economy: a conceptual review", Journal of Emerging Technologies and Innovative Research, Vol. 5 No. 9, pp. 421-431, doi: 10.1729/Journal.18350.

Chakrabarty, M. and Dutta, C. (2014), "Causes of digital divides in India and the role of indian libraries to bridge the gap", SRELS Journal of Information Management, Vol. 51 No. 1, available at: www.informaticsjournals.com/index.php/srels/article/view/3360

CIOL Bureau (2006), "India's first e-wallet launched. Retrieved october 2019, from CIOL bureau”, available at: www.ciol.com/indias-wallet-launched-2/

Internet skills as an influencer

Dey, S. and Raheem, E. (2016), "Multilevel multinomial logistic regression model for identifying factors associated with anemia in children 6-59 months in northeastern states of India", Cogent Mathematics, Vol. 3 No. 1, pp. 1-12, doi: 10.1080/23311835.2016.1159798.

Dutta, D. and Sarma, M.K. (2021), "Adoption of digital Innovation-Formulating adopter categories and levels of adoption in a digital sphere in an emerging economy", International Journal of Innovation and Technology Management, Vol. 17 No. 8, doi: 10.1142/S0219877020500595.

Ebermann, C., Piccinini, E., Busse, S., Leonhardt, D. and Kolbe, L. (2016), What Determines the Adoption of Digital Innovations by Digital Natives? - The Role of Motivational Affordances. Thirty Seventh International Conference on Information Systems, Dublin.

Financial Express (2018), "Swiggy expands services in 8 new cities including vijayawada, nashik, guwahati", from Financial Express, available at: www.financialexpress.com/industry/swiggyexpands-services-in-8-new-cities-including-vijayawada-nashik-guwahati/1320303/ (accessed October 2019)

Flipkart Stories (2017), "10 years of flipkart - a timeline of milestones", flipkart stories, available at: https://stories.flipkart.com/10-years-timeline-milestones/

Goh, E. and Sigala, M. (2020), "Integrating Information \& Communication Technologies (ICT) into classroom instruction: teaching tips for hospitality educators from a diffusion of innovation approach", Journal of Teaching in Travel and Tourism, pp. 1-10, doi: 10.1080/ 15313220.2020 .1740636 .

Grilo, L.M., Grilo, H.L., Gonçalves, S.P. and Junça, A. (2017), "Multinomial logistic regression in workers' healthinternational conference of computational methods in sciences and engineering 2017 (iccmse-2017)", DOI: 10.1063/1.5012392

Helsper, E. and van Deursen, A. (2017), "Do the rich get digitally richer? Quantity and quality of support for digital engagement", Information, Communication \& Society, Vol. 20 No. 5, pp. 700-714, doi: 10.1080/1369118X.2016.1203454.

Henfridsson, O., Mathiassen, L. and Svahn, F. (2014), "Managing technological change in the digital age: the role of architectural frames", Journal of Information Technology, Vol. 29 No. 1, pp. 27-43, $10.1057 \% 2$ Fjit.2013.30

Iyengar, J. and Belvalkar, M. (2010), Case Study of Online Banking in India:User Behaviors and Design Guidelines.: Human Work Interaction Design: Usability in Social, Cultural and Organizational Contexts, Springer, Berlin, pp. 180-188.

Jhanmir, S.F. and Cavadas, J. (2018), "Factors affecting late adoption of digital innovations", Journal of Business Research, Vol. 88, pp. 337-343.

Kaka, N., Madgavkar, A., Kshirsagar, A., Gupta, R., Manyika, J. and Bahl, K. et al. (2019), "Digital India: technology to transform a connected nation", from McKinsey Digital, available at: www.mckinsey.com/business-functions/mckinsey-digital/our-insights/digital-india-technology-totransform-a-connected-nation, (accessed 29 March 2020)

Keelery, S. (2020), "Internet usage in India - statistics \& facts", Statista, available at: www.statista.com/ topics/2157/internet-usage-in-india/

Khandelwal, S. (2019), "Believe it or not, IRCTC made it easier to book railway tickets - and could now get to run trains", from Scroll.in, available at: https://scroll.in/article/928933/believe-it-or- 

October 2019)

Kochar, R. (2016), "How big is the indian bill payment market?", from Entrepreneur India, available at: www.entrepreneur.com/article/273148 (accessed October 2019).

Livingstone, S., Ólafsson, K., Helsper, E.J., Lupiáñez-Villanueva, F., Veltri, G.A. and Folkvord, F. (2017), "Maximizing opportunities and MinimizingRisks for children online: the role of DigitalSkills in emerging strategies of ParentalMediation”, Journal of Communication, Vol. 67 No. 1, pp. 82-105. doi, doi: $10.1111 /$ jcom.12277.

Maiti, D., Castellacci, F. and Melchior, A. (2020), "Digitalisation and development: issues for India and beyond", in Maiti, D., Castellacci, F. and Melchior, A. (Eds), Digitalisation and Development, Springer, Singapore, available at: https://doi.org/10.1007/978-981-13-9996-1_1

Mehra, A. (2021), "Evolution of social media in India. Retrieved october 23, 2019, from silicon India blogs: hyperlink", available at: https://blogs.siliconindia.com/a2anuragmehra/Evolution_ of_Social_Media_in_India-bid-7PZ8vuDN20048653.html

O’Doherty, D., Lougheed, J., Hannigan, A., Last, J., Dromey, M., O’Tuathaigh, C., et al. (2019), "Internet skills of medical faculty and students: is there a difference?", BMC Medical Education, Vol. 19 No. 1, doi: 10.1186\%2Fs12909-019-1475-4.

Pew Research Center (2014), "Greater technology use linked to higher per capita income. Retrieved 2018, from pew research center", available at: www.pewresearch.org/global/2014/02/13/ developing-technology-use/

Pisano, G.P. (2014), "In defense of routine innovation", Harvard Business Review, available at: https:// hbr.org/2014/06/in-defense-of-routine-innovation

Rogers, E.M. (1983), Diffusion of Innovations, 3rd ed., The Free Press.

Sharma, A. (2018), "Understanding mahalnobis distance and its use, from analytics India magazine", available at: https://analyticsindiamag.com/understanding-mahalanobis-distance-and-its-usecases/ (accessed November 2019).

Singh, B. (2018), "Advantage Assam summit: investment of Rs 1,00,000 crore committed. The economic times", available at: https://economictimes.indiatimes.com/news/economy/finance/advantageassam-summit-investment-of-rs-100000-crore-committed/articleshow/62779498.cms

Talwar, S., Talwar, M., Kaur, P. and Dhir, A. (2020), "Consumers' resistance to digital innovations: a systematic review and framework development", Australasian Marketing Journal, Vol. 28 No. 4, pp. 286-299.

The Economic Times Travel (2018), "Travel, hospitality sector fast adopting digital technology", from The Economic Times, available at: https:/economictimes.indiatimes.com/industry/services/ travel/travel-hospitality-sector-fast-adopting-digital-technology/articleshow/63400253.cms

Thompson, V. (1965), "Bureaucracy and innovation", Administrative Science Quarterly, Vol. 10 No. 1, pp. 1-20, doi: 10.2307/2391646

van Deursen, A.J. and Helsper, E.J. (2018), "Do the rich get digitally richer? Quantity and quality of support for digital engagement”, Information, Communication \& Society, Vol. 20 No. 5, pp. 700-714, doi: 10.1080/1369118X.2016.1203454.

van Deursen, A.J., Helsper, E.J. and Eynon, R. (2016), "Development and validation of the internet skills scale (ISS)", Information, Communication \& Society, Vol. 19 No. 6, pp. 804-823, doi: 10.1080/ 1369118X.2015.1078834

van Deursen, A.J. and van Dijk, J.A. (2010a), "Internet skills and the digital divide", New Media \& Society, Vol. 13 No. 6, pp. 893-911, doi: 10.1177/1461444810386774.

van Deursen, A.J. and van Dijk, J.A. (2010b), "Measuring internet skills", International Journal of Human-Computer Interaction, Vol. 26 No. 10, pp. 891-916, doi: 10.1080/10447318. 2010.496338 . 
van Deursen, A.J. and van Dijk, J.A. (2014), Digital Skills Unlocking the Information Society, Palgrave Macmillan, New York, NY.

van Deursen, A. and van Dijk, J.A. (2018), "The first-level digital divide shifts from inequalities in physical access to inequalities in material access", New Media \& Society, Vol. 21 No. 2, pp. 354-375.

Vargo, S.L., Akaka, M.A. and Wieland, H. (2020), "Rethinking the process of diffusion in innovation: a service-ecosystems and institutional perspective", Journal of Business Research, Vol. 116, doi: 10.1016/j.jbusres.2020.01.038.

Internet skills as an influencer

Wiesböck, F. and Hess, T. (2020), “Digital innovations”, Electronic Markets, Vol. 30 No. 1, pp. 75-86.

Wittendorp, R. (2017), Modeling the Use of e-Government Services: The Role of Internet Skills, Support Sources, Gender, Age, Education, Internet Experience, Employment Rate and Income, University of Twente, Communication Studies.

Zimmermann, H.-D. (2016), “APIs and emerging economy - driving digital transformation through e-government", Liberec Informatics Forum, Liberec.

\section{Further reading}

IAMAI (2019), "India internet 2019", Neilsen, available at: https://cms.iamai.in/Content/Research Papers/d3654bcc-002f-4fc7-ab39-elfbeb00005d.pdf

\section{Corresponding author}

Dorothy Dutta can be contacted at: duttadorothy1@gmail.com

For instructions on how to order reprints of this article, please visit our website: 